\title{
Amiloride-Sensitive Nasal Potential Difference Is Not Changed by Estradiol and Progesterone Replacement But Relates to BPD or Death in a Randomized Trial on Preterm Infants
}

\author{
ULRICH H. THOME, AILEEN BISCHOFF, LUDWIG MAIER, FRANK POHLANDT, AND ANDREAS TROTTER
}

Section of Neonatology and Pediatric Critical Care Medicine [U.H.T., A.B., F.P., A.T.], University Hospital for Children and Adolescents, University of Ulm, 89075 Ulm, Germany; Pharmacy [L.M.], University of Ulm, 89069 Ulm, Germany

\begin{abstract}
Postnatal replacement of placental estradiol (E2) and progesterone $(\mathrm{P})$ in preterm infants may improve lung function, possibly mediated through enhanced epithelial $\mathrm{Na}^{+}$transport and alveolar fluid clearance. Preterm infants of $<29$ wk gestational age and $<1000 \mathrm{~g}$ birth weight requiring mechanical ventilation within $12 \mathrm{~h}$ of birth were randomized to receive either $2.5 \mathrm{mg} / \mathrm{kg}$ E2 and $22.5 \mathrm{mg} / \mathrm{kg} \mathrm{P}$ per day (E2/P), or vehicle placebo. Epithelial $\mathrm{Na}^{+}$ transport was assessed in 29 infants by measuring total nasal potential difference (NPD) and amiloride-sensitive NPD (ASNPD) on postnatal days of life 1,3,5, and 7, and mean values of all four measurements were calculated. Bronchopulmonary dysplasia (BPD) was defined as need for supplemental oxygen (goal $\mathrm{SaO}_{2} 90 \%$ ) or mechanical ventilation at $36 \mathrm{wk}$ corrected postmenstrual age. Mean ASNPD was $-6.5 \pm 2.8 \mathrm{mV}$ in infants receiving E2/P and $-6.1 \pm$ $2.6 \mathrm{mV}$ in infants receiving placebo (not significant). NPD was $-10.6 \pm 3.8 \mathrm{mV}$ and $-10.7 \pm 3.6 \mathrm{mV}$, respectively. The ASNPD was significantly higher in infants surviving without BPD $(-7.1 \pm$ $2.5 \mathrm{mV}$ ) than in infants developing BPD or not surviving $(-5.2 \pm$ $2.4 \mathrm{mV}$ ). In conclusion, ASNPD is not changed by postnatal replacement of E2 and P. Infants at high risk of developing BPD had lower ASNPD values in the immediate postnatal period. (Pediatr Res 60: 619-623, 2006)
\end{abstract}

A steady improvement of preterm infant survival and respiratory morbidity was observed from 1990 until 1998 and was attributed to the introduction of exogenous surfactant and antenatal steroids (1). Thereafter, the frequencies of adverse outcomes showed a plateau. Many infants still develop respiratory distress syndrome (RDS) despite surfactant administration, and the incidence of BPD appeared to be increasing again recently (1). Novel therapies are needed to further reduce respiratory morbidity.

Aside from producing surfactant, alveolar type II cells (AT2) are responsible for postnatal clearance of excess fluid from the airspaces by moving $\mathrm{Na}^{+}$ions from the apical to the basolateral side, which creates a measurable electrochemical

Received February 24, 2006; accepted July 4, 2006.

Correspondence: Ulrich H. Thome M.D., Section of Neonatology and Pediatric Critical Care, University Hospital for Children and Adolescents, University of Ulm, Eythstrasse 24, 89075 Ulm, Germany; e-mail: ulrich.thome@gmx.net

This work was supported by the Deutsche Forschungsgemeinschaft, DFG 395/2-1, 2-2.

Present address (A.T.): Center for Perinatal Medicine, Children's Hospital, University of Bonn, Sigmund-Freudstr. 25, 53105 Bonn, Germany.

DOI: 10.1203/01.pdr.0000242262.55324.aa gradient as well as an osmotic gradient driving water movement in the same direction (2). The importance of this process is best demonstrated by mice lacking the pore-forming $\alpha$-subunit of the epithelial $\mathrm{Na}^{+}$channel (ENaC), which invariably die from pulmonary edema and respiratory failure within $40 \mathrm{~h}$ of birth (3). Infant RDS may in part be caused by inadequate epithelial $\mathrm{Na}^{+}$transport (4). Furthermore, survival of adults suffering from acute RDS has been related to alveolar fluid clearance (5). Lung water content (6) and epithelial ion transport (7) have also been related to pulmonary compliance.

Epithelial ion transport is inaccessible inside the lungs of intact subjects, but the transport mechanisms are expressed in all respiratory epithelia including the trachea and nose. The resulting electrochemical gradient can be readily measured at the nasal epithelium and is known as the NPD. The contribution of ENaC-dependent $\mathrm{Na}^{+}$transport to total NPD can be determined by the ASNPD, defined as the decrease in potential following the application of the $\mathrm{ENaC}$ blocker amiloride. Reduced NPD and ASNPD, indicating subnormal epithelial $\mathrm{Na}^{+}$transport, have been associated with RDS and reduced pulmonary compliance $(7,8)$.

Animal and cell culture experiments indicate that E2 and P participate in the regulation of epithelial $\mathrm{Na}^{+}$transport and thus alveolar fluid clearance $(9,10)$ (Thome et al., Pediatric Academic Societies Meeting, Washington, DC, 2005). Therefore, preterm withdrawal of placental E2 and P supply after preterm birth may be partly responsible for poor alveolar fluid clearance and poor lung function of preterm infants $(8,11)$. Herein, we measured NPD and ASNPD in preterm infants participating in a randomized, controlled, double-blind study of E2 and P replacement (Trotter et al., Pediatric Academic Societies Meeting, Washington, DC, 2005). We hypothesized that E2 and P replacement would increase ASNPD in preterm infants. Secondary hypotheses were that E2 and P would increase total NPD and that a low ASNPD would be associ-

Abbreviations: AISNPD, amiloride-insensitive nasal potential difference; ASNPD, amiloride-sensitive nasal potential difference; BPD, bronchopulmonary dysplasia; E2, estradiol; ENaC, epithelial sodium channel; Na,K-ATPase, sodium-potassium exchanging adenosine triphosphatase; NPD, nasal potential difference; P, progesterone; RM-ANOVA, repeated-measures analysis of variance 
ated with a higher oxygenation index or BPD or death combined.

\section{METHODS}

Subjects. Preterm infants with a birth weight $<1000 \mathrm{~g}$ and a gestational age $<29$ completed weeks requiring mechanical ventilation within $12 \mathrm{~h}$ of birth were eligible for participation in a randomized, double-blind, placebocontrolled trial of E2 and P replacement (Trotter et al., Pediatric Academic Societies Meeting, Washington, DC, 2005). Exclusion criteria were congenital malformations and chromosomal anomalies. All infants enrolled after Sepember 1, 2001, were eligible for NPD measurement. The study and the ancillary protocol governing NPD measurement were approved by the Institutional Review Board of the University of Ulm, Germany, and written informed consent was obtained from the parents of all infants.

Study intervention. Enrolled infants received an i.v. infusion of a standard $20 \%$ lipid emulsion (Lipofundin, B. Braun, Melsungen, Germany), diluted with water to $5 \%$, at a rate of $15 \mathrm{~mL} / \mathrm{kg} / \mathrm{d}$, resulting in $0.75 \mathrm{~g} / \mathrm{kg} / \mathrm{d}$ lipid intake. For infants randomized to E2 and P replacement, the 5\% lipid emulsion contained $0.165 \mathrm{~g} / \mathrm{L}$ estradiol hemihydrate and $1.5 \mathrm{~g} / \mathrm{L}$ progesterone, corresponding to $2.5 \mathrm{mg} / \mathrm{kg} / \mathrm{d} \mathrm{E} 2$ and $22.5 \mathrm{mg} / \mathrm{kg} / \mathrm{d} \mathrm{P}$. The dose was tailored to maintain E2 and P plasma levels in the range known for normal human fetuses in utero, i.e. $2000-6000 \mathrm{pg} / \mathrm{mL}$ E2 and $300-600 \mathrm{ng} / \mathrm{mL} \mathrm{P}$, respectively (12). Both study emulsions had equal appearance and were to be given continuously for the first 14 to 28 postnatal days of life unless hypertriglyceridemia $>3 \mathrm{mM}$ was detected. Plasma levels of E2 and P were determined on days of life 1,3 , and 7 by a standard radioimmunoassay ( $17 \beta$-Estradiol ${ }^{125}$ I RIA Kit, Progesterone ${ }^{125}$ I RIA Kit, ICN Biomedicals, Costa Mesa, CA) (12).

Nasal potential difference measurement. Setup. The measurement circuits (Fig. 1) were built of disposable infusion system supplies and perfused with sterile Ringer's solution containing in mmol/L: $\mathrm{Na}^{+} 147.2, \mathrm{~K}^{+} 4.0, \mathrm{Ca}^{2+}$ $2.25, \mathrm{Cl}^{-} 155.7$ (B. Braun). A 5-Chariere umbilical line was used as nasal catheter. For the electrical connections, two autoclaved pointed chlorided silver wires $(\mathrm{Ag} / \mathrm{AgCl}$ electrodes) were inserted through rubber-capped injection sites in blind-ending infusion lines (MX1798-LR, Medex Medical, Lancashire, UK), which were filled with the same solution but not perfused. One was connected to the nasal catheter and the other (reference electrode) to an intravascular access line of the infant, using three-way stopcocks. An additional three-way stopcock allowed switching the perfusion of the nasal catheter to Ringer's solution with additional $10^{-4} \mathrm{~mol} / \mathrm{L}$ amiloride (mixed and sterilized by L.M. in our hospital pharmacy). The two $\mathrm{Ag} / \mathrm{AgCl}$ electrodes were connected by a shielded cable to an Iso-DAM amplifier (World Precision Instruments, Sarasota, FL) featuring an optically isolated battery driven preamplifier with an input impedance of $>10^{12} \Omega$. The amplified output signal was measured and digitized using a digital multimeter with computer interface (Voltcraft M-3850, Conrad Elektronik, Hirschau, Germany) and recorded on a standard laptop computer running Digiscope software (Conrad).

Measurement process. Measurements were performed on postnatal days of life $1,3,5$, and 7 . The nasal perfusion system was placed in the infant's incubator for prewarming and the perfusion pump set to $5 \mathrm{~mL} / \mathrm{h}$. The infusion lines with the $\mathrm{Ag} / \mathrm{AgCl}$ electrodes were short circuited. When the initial drift

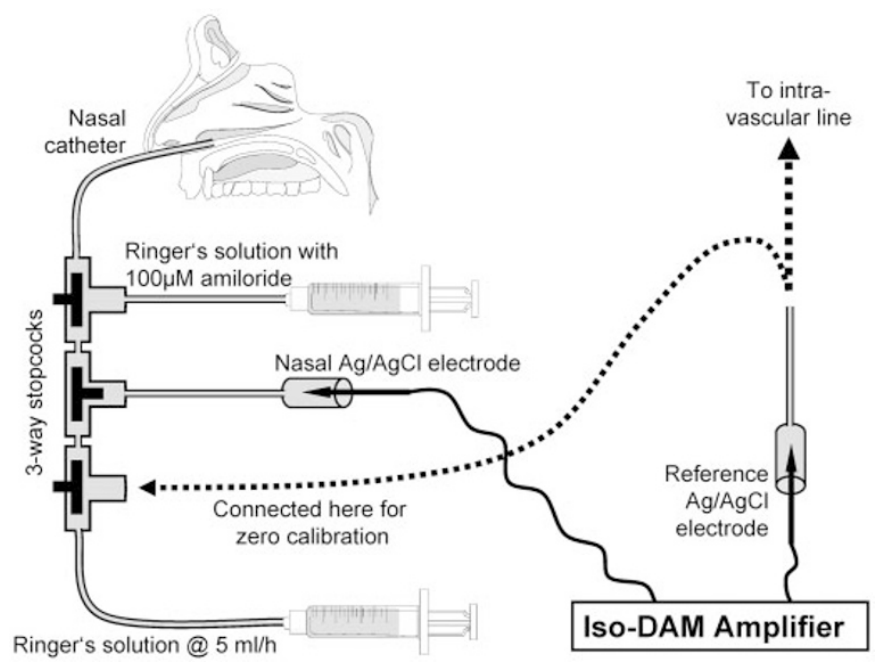

Figure 1. Schematic diagram of the measurement circuits (see text). had ceased, the IsoDAM was carefully zeroed and the reference electrode connected to an intravascular access line of the infant. Umbilical or radial artery lines were preferred, as they generally contained normal or one-half normal saline solution and had a low electrical resistance. Infants were nasally intubated or received nasopharyngeal continuous positive airway pressure (CPAP) through a single tube inserted in one nostril, so the other nostril was always available for NPD measurement. The nasal catheter was slowly advanced into the lower turbinate of the nostril in search of the site with the highest (most negative) potential, and fixed there with tape if necessary. When the potential reading had stabilized, the perfusion of the nasal catheter was switched to the amiloride-containing solution and the reduction of the potential was recorded. Thereafter, the nasal perfusion system was removed and the lines with the $\mathrm{Ag} / \mathrm{AgCl}$ electrodes were short circuited again to check for drifts. Infants were not sedated or paralyzed, very active infants occasionally received a few drops of $10 \%$ glucose solution onto their tongue.

Data analysis and statistics. The digitized records were displayed graphically and mean values from artifact-free 15-s intervals obtained by a selfwritten macro running under Excel 97 (Microsoft, Redmond, OR). AISNPD was the NPD after instilling amiloride. ASNPD was the difference between NPD and AISNPD. Differences of ASNPD and NPD between groups were analyzed by a repeated-measures analysis of variance (RM-ANOVA) using a first-order autoregressive process as a model, including the possibility of statistical correction for gestational age and birth weight (Mixed procedure of SAS software, version 8.2, SAS Institute, Cary, NC). Mean potential difference values were calculated as mean values of the four measurements obtained from each patient at different time points. A receiver operating characteristic (ROC) analysis was performed to evaluate the association of ASNPD with the development of BPD or death. Clinical parameters, such as ventilator settings, were recorded at the times of NPD measurements.

When this study was started, 28 patients remained to be enrolled in the main trial. Assuming a standard deviation (SD) of $2 \mathrm{mV}$ (8), an ASNPD difference of $2.2 \mathrm{mV}$ between groups would have been detectable by a $t$ test, which was of similar magnitude as differences found between infants with and without RDS (8). A somewhat higher statistical power was expected when using a RM-ANOVA. Demographic variables and clinical outcome parameters were analyzed by $t$, Mann-Whitney $U$, and Fisher exact tests as appropriate. BPD was defined as transcutaneously measured oxygen saturation $\left(\mathrm{SaO}_{2}\right)$ below $90 \%$ in room air and need of supplemental oxygen for more than $30 \mathrm{~min}$ at a corrected postmenstrual age of $36 \mathrm{wk}+0 \mathrm{~d}$, which is equivalent to moderate or severe BPD by the National Institutes of Child Health and Human Development consensus (13). Intraventricular hemorrhages were classified according to Papile et al. (14). The oxygenation index was calculated according to Hallman et al. (15) by multiplying the mean airway pressure (in mbar) with the fraction of inspired oxygen and the factor 100, and dividing the result by the arterial partial pressure of $\mathrm{O}_{2}$ (in $\mathrm{mm} \mathrm{Hg}$ ).

\section{RESULTS}

From September 2001 until February 2003, 29 infants were recruited to the main trial and received $\mathrm{E} 2$ and $\mathrm{P}$ or placebo infusions as well as NPD measurements. During the same time, 46 additional infants of less than 29 wk gestational age and less than $1000 \mathrm{~g}$ birth weight were admitted to our unit but not enrolled because they did not require mechanical ventilation within $12 \mathrm{~h}$ of birth $(n=34)$ or parental consent was not available $(n=12)$. Infants receiving E2 and P supplementation were similar to infants receiving placebo in their baseline characteristics (Table 1). All infants received at least one dose of surfactant, with no difference between groups (not shown). Unilateral nasal CPAP was applied in $20 \%$ of the infants who became extubated during the study period. The other infants remained on mechanical ventilation. Average nasal recording depth was $2 \mathrm{~cm}$ from the nostril.

ASNPD was not different between groups at any time during the study period (Fig. 2 and Table 2). Furthermore, there was no difference in total NPD (Table 2). Six infants had to be taken off study infusion during the first week of life because of hypertriglyceridemia. Excluding those infants from the analysis did not influence the statistical ASNPD and NPD 
Table 1. Demographic data

\begin{tabular}{lccc}
\hline & $\begin{array}{c}\text { E2 and P } \\
(n=15)\end{array}$ & $\begin{array}{c}\text { Placebo } \\
(n=14)\end{array}$ & $p$ \\
\hline Gestational age (wk)* & $25.1 \pm 1.3$ & $25.7 \pm 1.1$ & 0.14 \\
Birth weight $(\mathrm{g})^{*}$ & $651 \pm 163$ & $630 \pm 166$ & 0.74 \\
Male & $9(60)$ & $7(50)$ & 0.72 \\
Prenatal steroids: & $11 / 2 / 2$ & $13 / 1 / 0$ & 0.36 \\
$\quad$ complete/partial/none & $10(67)$ & $13(93)$ & 0.17 \\
Cesarean section & $8(5-10)$ & $7(5-9)$ & 0.30 \\
5-min Apgar score (range) & & & \\
\hline
\end{tabular}

$*$ Mean $\pm \mathrm{SD}, t$ test, all others: number (\%), Fisher exact test.

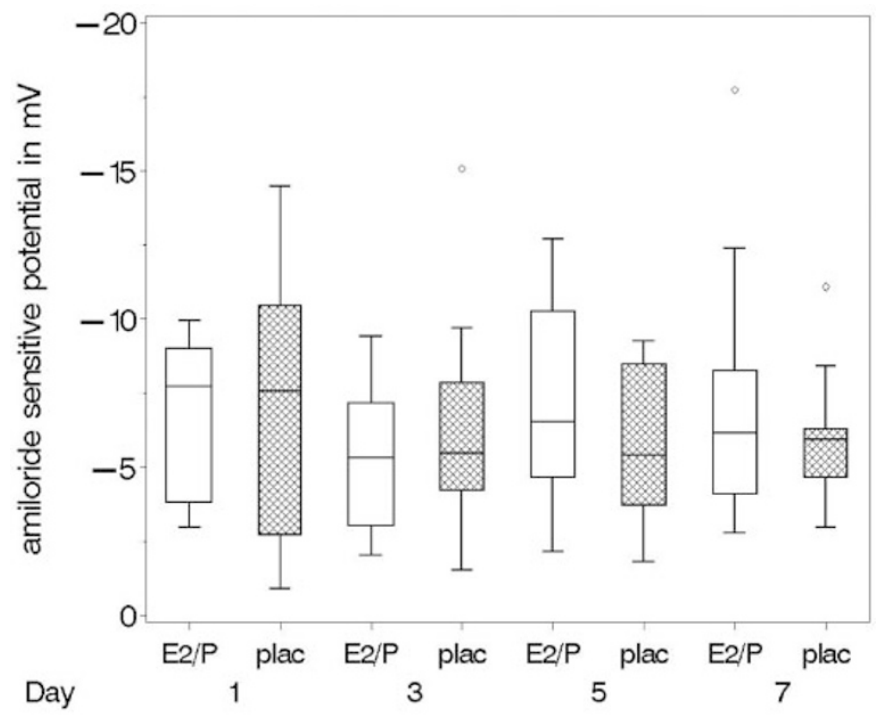

Figure 2. ASNPD in infants receiving i.v. E2 and $\mathrm{P}(n=15)$ or placebo (plac, $n=14$ ) on postnatal days of life 1,3,5, and 7. The graph shows median values (horizontal line), 25th and 75th percentiles (boxes), 5th and 95th percentiles (whiskers), and extreme values (dots). No significant difference was detectable.

Table 2. Outcome

\begin{tabular}{lccc}
\hline & $\begin{array}{c}\text { E2 and P } \\
(n=15)\end{array}$ & $\begin{array}{c}\text { Placebo } \\
(\mathrm{n}=14)\end{array}$ & $p$ \\
\hline Mortality & $2(13)$ & $0(0)$ & 0.48 \\
IVH grade 3-4 & $2(13)$ & $3(21)$ & 0.65 \\
BPD or death & 5 & 7 & 0.46 \\
$\begin{array}{l}\text { Duration of mechanical } \\
\quad \text { ventilation (d)* }\end{array}$ & $39(1-86)$ & $22(1-191)$ & 0.88 \\
No. of infants remaining & $15,15,13,11$ & $14,14,13,12$ & n.s. \\
$\quad$ on study infusion on & & & \\
$\quad$ d 1, 3, 5, 7 & & & \\
Duration of study infusion $(\mathrm{d})^{*}$ & $17(3-28)$ & $20(3-28)$ & 0.65 \\
ASNPD (mV) $\dagger$ & $-6.5 \pm 2.8$ & $-6.1 \pm 2.6$ & 0.64 \\
Total NPD (mV) $\dagger$ & $-10.6 \pm 3.8$ & $-10.7 \pm 3.6$ & 0.90 \\
\hline
\end{tabular}

Number (\%), Fisher exact test.

* Median (minimum-maximum), Kaplan-Meier life table analysis with log-rank test.

$\dagger$ Mean \pm SD, RM-ANOVA.

results (not shown). There was no interaction with the infants' $\operatorname{sex}(p=0.98$, data not shown). Mortality, incidence of intraventricular hemorrhage (IVH) and BPD or death, and duration of mechanical ventilation were similar in both groups (Table 2).

$\mathrm{E} 2$ and $\mathrm{P}$ serum concentrations are listed in Table 3. In the
Table 3. E2 and $P$ serum concentrations

\begin{tabular}{cccc}
\hline & Day of life & E2 and P $(n=15)$ & Placebo $(n=14)$ \\
\hline E2 $(\mathrm{pg} / \mathrm{mL})$ & 1 & $2644(1622-6518)$ & $251(117-694)$ \\
& 3 & $6657(827-15,086)$ & $306(105-453)$ \\
$\mathrm{P}(\mathrm{ng} / \mathrm{mL})$ & 7 & $4180(1440-5744)$ & $188(33-698)$ \\
& 1 & $302(190-688)$ & $2(0-4)$ \\
& 3 & $478(52-868)$ & $4(1-7)$ \\
& 7 & $376(226-572)$ & $3(0-5)$ \\
\hline
\end{tabular}

Median values (minimum-maximum) are given.

Table 4. ASNPD by OI averaged over the first $7 d$ of life

\begin{tabular}{lccc}
\hline & $\begin{array}{c}\text { Mean OI }>4 \\
(n=13)\end{array}$ & $\begin{array}{c}\text { Mean OI } \leq 4 \\
(n=16)\end{array}$ & $p$ \\
\hline Gestational age (wk) & $25.7 \pm 1.3$ & $25.1 \pm 1.1$ & 0.17 \\
Birth weight $(\mathrm{g})$ & $585 \pm 155$ & $685 \pm 158$ & 0.10 \\
Male & $8(62)$ & $8(50)$ & 0.71 \\
ASNPD (mV) & $-5.3 \pm 2.6$ & $-7.1 \pm 2.5$ & $<0.05^{*}$ \\
NPD (mV) & $-9.6 \pm 4.0$ & $-11.5 \pm 3.2$ & 0.09 \\
\hline
\end{tabular}

Mean \pm SD are given. ASNPD and NPD tested by RM-ANOVA.

* The $p$ values are 0.041 without correction, 0.040 with correction for gestational age, and 0.065 with correction for birth weight.

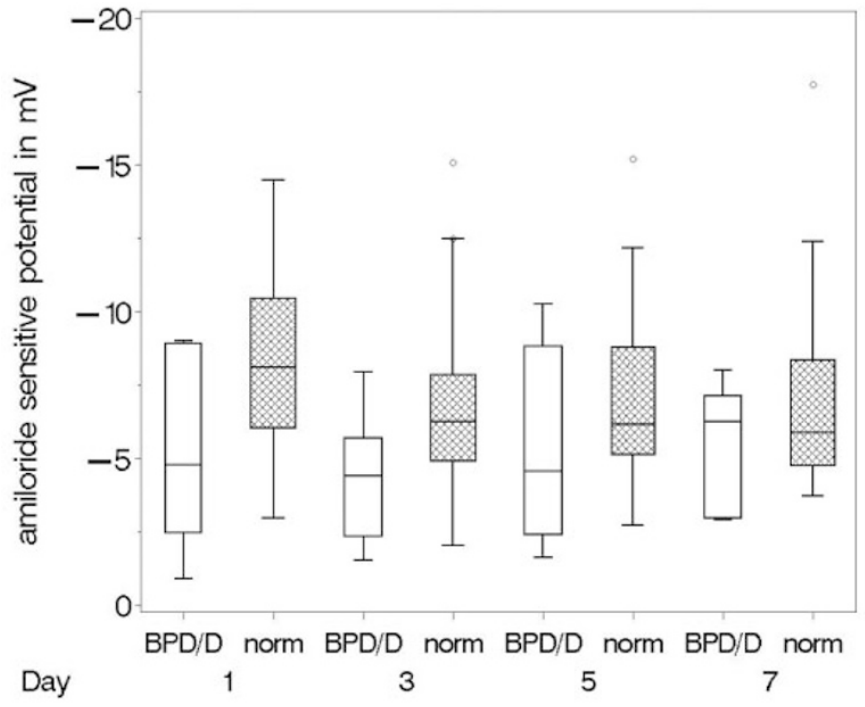

Figure 3. ASNPD in infants subsequently developing BPD or dying (BPD/D, $n=12$ ) or surviving without BPD (norm, $n=17$ ) on postnatal days of life $1,3,5$, and 7 . The graph shows median values (horizontal line), 25th and 75th percentiles (boxes), 5th and 95th percentiles (whiskers), and extreme values $($ dots $)$. Values were significantly higher in infants surviving without BPD ( $p$ $<0.05$, RM-ANOVA).

infants on E2 and $\mathrm{P}$ supplementation, only five E2 values were below the desired level of at least $2000 \mathrm{pg} / \mathrm{mL}$. P values above $300 \mathrm{ng} / \mathrm{mL}$ were achieved in half the infants on $\mathrm{d} 1$ and 3; values were lower thereafter. Excluding NPD measurements obtained on days with E2 or P levels below the desired range from the analysis did not change the statistical results (data not shown).

Infants with an average oxygen index $(\mathrm{OI})>4$ over the first $7 \mathrm{~d}$ of life were similar to infants with an average OI $\leq 4$ with regard to birth weight or gestational age, but had significantly lower ASNPD (Table 4). Furthermore, infants who died or developed BPD had significantly lower ASNPD than infants surviving without BPD (Fig. 3), whereas there were no sig- 
Table 5. ASNPD by BPD or death and survival without BPD

\begin{tabular}{lccc}
\hline & $\begin{array}{c}\text { BPD or death } \\
(n=12)\end{array}$ & $\begin{array}{c}\text { Survived without BPD } \\
(n=17)\end{array}$ & $p$ \\
\hline Gestational age (wk) & $25.8 \pm 1.4$ & $25.1 \pm 1.0$ & 0.12 \\
Birth weight $(\mathrm{g})$ & $579 \pm 142$ & $684 \pm 165$ & 0.09 \\
Male & $8(67)$ & $8(47)$ & 0.45 \\
ASNPD (mV) & $-5.2 \pm 2.4$ & $-7.1 \pm 2.6$ & $<0.05^{*}$ \\
NPD $(\mathrm{mV})$ & $-9.4 \pm 3.4$ & $-11.6 \pm 3.7$ & 0.07 \\
\hline
\end{tabular}

Mean \pm SD are given. ASNPD and NPD tested by RM-ANOV A.

* The $p$ values are 0.036 without correction, 0.033 with correction for gestational age, and 0.058 with correction for birth weight.

nificant differences in birth weight or gestational age (Table 5). The difference was largest on $\mathrm{d} 1$ and diminished during the first week of life and was robust to correction for gestational age. However, with correction for birth weight, the difference was no longer significant (Tables 4 and 5). The ROC analysis revealed that an ASNPD value $<6.0 \mathrm{mV}$ on $\mathrm{d}$ 3 was associated with the development of BPD or death with a sensitivity of $83 \%$ and a specificity of 59\% (data not shown). ASNPD and NPD were not correlated to gestational age (Spearman's rho 0.08 and $0.08, p=0.39$ and $p=0.42$, respectively, not shown).

\section{DISCUSSION}

ASNPD and total NPD were not significantly different between infants receiving E2/P or placebo infusions. The mean difference of ASNPD was only $0.4 \mathrm{mV}$. To show this as a significant difference would have required approximately 800 patients. Although these findings do not rule out that E2/P as used in this study may weakly increase nasal epithelial $\mathrm{Na}^{+}$ transport, any effects are probably small. If the alveolar epithelium responds similarly, it is doubtful that such a small potential difference, if real, would be associated with a clinically important difference in alveolar fluid clearance.

In swine, we have demonstrated a significant reduction of alveolar fluid clearance after pharmacologic E2 and P withdrawal during pregnancy (10). However, as alveolarization was also impaired, it is possible that the decreased alveolar fluid clearance was an indirect effect mediated through a reduced number of lung epithelial cells, rather than an impaired $\mathrm{Na}^{+}$transport per cell.

Measurements of ENaC mRNA in lung tissue from juvenile and ovariectomized rats indicated stronger effects of $\mathrm{E} 2$ and $\mathrm{P}$ on ENaC subunit expression (9). However, even when mRNA levels are high, translation of mRNA, assembly of proteins, and insertion into the cell membrane are important regulated steps that may reduce differences present at the mRNA level. Furthermore, actual magnitude of $\mathrm{Na}^{+}$transport depends not only on $\mathrm{ENaC}$ availability, but also on $\mathrm{Na}, \mathrm{K}-\mathrm{ATPase}$ function. Overexpressing $\mathrm{Na}, \mathrm{K}-\mathrm{ATPase}$ by an adenoviral vector was sufficient to increase $\mathrm{Na}^{+}$transport in isolated cultured fetal rat alveolar cells (16). In the same cell culture model, E2 and $\mathrm{P}$ exposure during culture increased $\mathrm{Na}^{+}$transport by increasing $\mathrm{ENaC}$ and sodium-potassium exchanging adenosine triphosphatase (Na,K-ATPase) activity (9) (Thome et al., Pediatric Academic Societies Meeting, 2005), in contrast to the findings reported here. However, the infants studied here were, at least when considering the gestational age, less mature than the juvenile rats (9) or 19-d rat fetuses $(86 \%$ of term) (Thome et al., Pediatric Academic Societies Meeting, 2005) from which the cells were isolated for the experimental studies. Although low ENaC mRNA levels were detected in rat fetuses of any gestational age (17), the prenatal increase of $\mathrm{ENaC}$ and $\mathrm{Na}, \mathrm{K}$-ATPase subunit expression was not observed before $19-22 \mathrm{~d}$ of gestation, i.e. shortly before term birth at $22 \mathrm{~d}$ (17-20). If the ontogeny of $\mathrm{ENaC}$ and $\mathrm{Na}, \mathrm{K}-\mathrm{ATPase}$ follows a similar pattern in human fetuses and preterm infants (21), the participants of our study would have been born long before the prenatal increase of $\mathrm{ENaC}$ and $\mathrm{Na}, \mathrm{K}$-ATPase subunit expression (22). On the other hand, prenatal steroid treatment may advance the expression of $\mathrm{ENaC}$ and $\mathrm{Na}, \mathrm{K}$ ATPase $(21,23)$, which may also influence susceptibility to other factors such as E2 and P. Therefore, the infants may have been too immature to respond to $\mathrm{E} 2$ and $\mathrm{P}$ with a strong increase of $\mathrm{ENaC}$ and $\mathrm{Na}, \mathrm{K}$-ATPase expression, which would have been needed to produce measurable effects.

Previous studies have demonstrated a correlation of NPD and ASNPD with gestational age, postnatal age, and the degree of lung disease $(8,24)$. In our extremely preterm infants, we have found lower values for ASNPD and NPD than previously described in more mature preterm infants $(8,24)$, term infants $(7,25,26)$, and adults (27) and no increase during the first week of life or correlation to gestational age. The reason may again be the extreme immaturity, rendering the infants unable to increase their ASNPD and NPD during the first postnatal week. Furthermore, infants born before the ontogenetically determined increase of $\mathrm{ENaC}$ expression would not be expected to show a correlation of ASNPD and NPD to gestational age.

Despite the extreme immaturity and unlike previous findings (8), we found a net absorptive epithelium in the nasal cavity, as demonstrated by more than 50\% of total NPD being amiloride sensitive, a transport pattern similar to cultured adult murine tracheocytes (28). The extreme immaturity may have resulted not only in low activity of amiloride-sensitive pathways, but also amiloride-insensitive ion transporting pathways. In that situation, one would find a higher proportion of amiloride-sensitive pathways despite a low overall transport activity, the latter indicated by the low total NPD values. Whether absorptive processes also dominate inside the infants' lungs is unknown because simultaneous measurements of nasal and alveolar transport are not available. All we know is that lung function and lung water content correlate with ASNPD $(7,8,21)$, which was confirmed in our study by the association of lower ASNPD values with a higher OI. Furthermore, infants developing BPD or dying were characterized by a lower ASNPD than infants surviving without BPD, which was, however, confounded by the birth weight. The association of ASNPD and the development of BPD or death was strongest on $\mathrm{d} 3$, achieving higher values for sensitivity and specificity than those previously described for the alveolar-toarterial partial pressure difference of oxygen $\left(\mathrm{AaDO}_{2}\right)$ and the OI (29). The association of ASNPD with BPD or death, however, requires confirmation in a larger cohort before clinical use. 
After instilling amiloride, a considerable potential remained, which is probably mainly caused by residual $\mathrm{Cl}^{-}$ secretion, in analogy to tracheocyte (28) and alveolar cell (23) cultures. However, we have made no attempts to investigate this hypothesis because suitable $\mathrm{Cl}^{-}$channel blockers for in vivo use were not available.

NPD is generally measured with calomel electrodes coupled by salt-agar bridges (25), a cumbersome technique for use inside an incubator. Disposable intensive care unit supplies and autoclaved $\mathrm{Ag} / \mathrm{AgCl}$ electrodes allowed us to build simple and completely sterile measurement circuits. As the injection port tubings with the $\mathrm{AgCl}$ electrodes were not perfused, only diffusion might have carried potentially toxic $\mathrm{Ag}^{+}$ions into the perfused parts of the circuit leading to the nasal epithelium. Diffusion, however, was limited by the length and small diameter of the tubes. Experiments with dyed solutions did not show any movement of the dye for the duration of a measurement. Calculations using the second law of Fick and the solubility and mobility of $\mathrm{AgCl}$ revealed that diffusion was negligible, as less than $10^{-25} \mathrm{~mol} / \mathrm{L} \mathrm{Ag}^{+}$(less than 1 atom) might have actually reached the nasal epithelium or the percutaneous catheter, much less than the $10^{-7} \mathrm{~mol} / \mathrm{L}$ needed to influence epithelial potentials (30).

In conclusion, E2/P replacement of ventilated preterm infants did not increase ASNPD and NPD, and therefore may not influence respiratory epithelial $\mathrm{Na}^{+}$transport to a clinically important extent. Low values for ASNPD and NPD were found in this extremely preterm cohort. ASNPD values related to short- and long-term respiratory disease and, if confirmed in a larger cohort, may identify infants at increased risk of death or survival with BPD.

\section{REFERENCES}

1. St John EB, Carlo WA 2003 Respiratory distress syndrome in VLBW infants: changes in management and outcomes observed by the NICHD Neonatal Research Network. Semin Perinatol 27:288-292

2. Matalon S, O'Brodovich H 1999 Sodium channels in alveolar epithelial cells: molecular characterization, biophysical properties, and physiological significance. Annu Rev Physiol 61:627-661

3. Hummler E, Barker P, Gatzy J, Beermann F, Verdumo C, Schmidt A, Boucher R, Rossier BC 1996 Early death due to defective neonatal lung liquid clearance in $\alpha$ ENaC-deficient mice. Nat Genet 12:325-328

4. O'Brodovich HM 1996 Immature epithelial $\mathrm{Na}+$ channel expression is one of the pathogenetic mechanisms leading to human neonatal respiratory distress syndrome. Proc Assoc Am Physicians 108:345-355

5. Ware LB, Matthay MA 2001 Alveolar fluid clearance is impaired in the majority of patients with acute lung injury and the acute respiratory distress syndrome. [see comments.]. Am J Respir Crit Care Med 163:1376-1383

6. Flemmer A, Simbruner G, Muenzer S, Proquitte H, Haberl C, Nicolai T, Leiderer R 2000 Effect of lung water content, manipulated by intratracheal furosemide, surfactant, or a mixture of both, on compliance and viscoelastic tissue forces in lunglavaged newborn piglets. [see comment]. Crit Care Med 28:1911-1917

7. Helve O, Pitkanen O, Kirjavainen T, Andersson S 2005 Sodium transport in airway epithelium correlates with lung compliance in healthy newborn infants. J Pediatr $146: 273-276$
8. Barker PM, Gowen CW, Lawson EE, Knowles MR 1997 Decreased sodium ion absorption across nasal epithelium of very premature infants with respiratory distress syndrome [see comments]. J Pediatr 130:373-377

9. Sweezey N, Tchepichev S, Gagnon S, Fertuck K, O'Brodovich H 1998 Female gender hormones regulate mRNA levels and function of the rat lung epithelial $\mathrm{Na}$ channel. Am J Physiol 274:C379-C386

10. Trotter A, Ebsen M, Kiossis E, Meggle S, Kueppers E, Beyer C, Pohlandt F, Maier L, Thome UH 2006 Prenatal estrogen and progesterone deprivation impairs alveolar formation and fluid clearance of newborn piglets. Pediatr Res 60:60-64

11. Trotter A, Maier L, Grill HJ, Kohn T, Heckmann M, Pohlandt F 1999 Effects of postnatal estradiol and progesterone replacement in extremely preterm infants. J Clin Endocrinol Metab 84:4531-4535

12. Trotter A, Maier L, Grill HJ, Wudy SA, Pohlandt F 1999 17Beta-estradiol and progesterone supplementation in extremely low-birth-weight infants. Pediatr Res 45:489-493

13. Ehrenkranz RA, Walsh MC, Vohr BR, Jobe AH, Wright LL, Fanaroff AA, Wrage LA, Poole K National Institutes of Child Health and Human Development Neonatal Research Network 2005 Validation of the National Institutes of Health Consensus Definition of Bronchopulmonary Dysplasia. Pediatrics 116:1353-1360.

14. Papile LA, Burstein J, Burstein R, Koffler H 1978 Incidence and evolution of subependymal and intraventricular hemorrhage: a study of infants with birth weights less than 1,500 gm. J Pediatr 92:529-534

15. Hallman M, Merritt TA, Jarvenpaa AL, Boynton B, Mannino F, Gluck L, Moore T, Edwards D 1985 Exogenous human surfactant for treatment of severe respiratory distress syndrome: a randomized prospective clinical trial. J Pediatr 106:963-969

16. Thome U, Chen L, Factor P, Dumasius V, Freeman B, Sznajder JI, Matalon S 2001 $\mathrm{Na}, \mathrm{K}-\mathrm{ATPase}$ gene transfer mitigates oxidant-induced decrease of active sodium transport in rat fetal ATII cells. Am J Respir Cell Mol Biol 24:245-252

17. O’Brodovich H, Canessa C, Ueda J, Rafii B, Rossier BC, Edelson J 1993 Expression of the epithelial $\mathrm{Na}+$ channel in the developing rat lung. Am J Physiol 265:C491C496

18. Ingbar DH, Weeks CB, Gilmore-Hebert M, Jacobsen E, Duvick S, Dowin R, Savik SK, Jamieson JD 1996 Developmental regulation of Na,K-ATPase in rat lung. Am J Physiol Lung Cell Mol Physiol 270:L619-L629

19. O'Brodovich H, Staub O, Rossier BC, Geering K, Kraehenbuhl JP 1993 Ontogeny of alpha 1- and beta 1-isoforms of $\mathrm{Na}(+)-\mathrm{K}(+)$-ATPase in fetal distal rat lung epithelium. Am J Physiol 264:C1137-C1143

20. Tchepichev S, Ueda J, Canessa C, Rossier BC, O’Brodovich H 1995 Lung epithelial Na channel subunits are differentially regulated during development and by steroids. Am J Physiol 269:C805-C812

21. Helve O, Pitkanen OM, Andersson S, O’Brodovich H, Kirjavainen T, Otulakowski G 2004 Low expression of human epithelial sodium channel in airway epithelium of preterm infants with respiratory distress. Pediatrics 113:1267-1272

22. Ingbar DH, Duvick S, Savick SK, Schellhase DE, Detterding R, Jamieson JD, Shannon JM 1997 Developmental changes of fetal rat lung Na-K-ATPase after maternal treatment with dexamethasone. Am J Physiol Lung Cell Mol Physiol 272:L665-L672

23. Thome UH, Davis IC, Nguyen SV, Shelton BJ, Matalon S 2003 Modulation of sodium transport in fetal alveolar epithelial cells by oxygen and corticosterone. Am J Physiol Lung Cell Mol Physiol 284:L376-L385

24. Gaillard EA, Shaw NJ, Wallace HL, Subhedar NV, Southern KW 2005 Nasal potential difference increases with gestation in moderately preterm neonates on the first postnatal day. Arch Dis Child Fetal Neonatal Ed 90:F172-F173

25. Gowen CW, Lawson EE, Gingras J, Boucher RC, Gatzy JT, Knowles MR 1988 Electrical potential difference and ion transport across nasal epithelium of term neonates: correlation with mode of delivery, transient tachypnea of the newborn, and respiratory rate. J Pediatr 113:121-127

26. Gaillard EA, Shaw NJ, Wallace HL, Subhedar NV, Southern KW 2003 Airway ion transport on the first postnatal day in infants delivered vaginally or by elective cesarean section. Pediatr Res 54:58-63

27. Sartori C, Duplain H, Lepori M, Egli M, Maggiorini M, Nicod P, Scherrer U 2004 High altitude impairs nasal transepithelial sodium transport in HAPE-prone subjects. [see comment]. Eur Respir J 23:916-920

28. Thome U, Lazrak A, Chen L, Kirk MC, Thomas MJ, Forman HJ, Matalon S 2003 Novel SIN-1 reactive intermediates modulate chloride secretion across murine airway cells. Free Radic Biol Med 35:662-675

29. Srisuparp P, Marks JD, Khoshnood B, Schreiber MD 2003 Predictive power of initial severity of pulmonary disease for subsequent development of bronchopulmonary dysplasia. Biol Neonate 84:31-36

30. Klyce SD, Marshall WS 1982 Effects of $\mathrm{Ag}+$ on ion transport by the corneal epithelium of the rabbit. J Membr Biol 66:133-144 